Appl. Phys. B 43, 263-271 (1987)

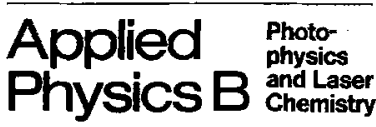

(C) Springer-Verlag 1987

\title{
Characteristics of an $\mathrm{x}$-Ray Preionized TEA CO Laser
}

\author{
R. J. Zuidema and G. J. Ernst \\ Twente University of Technology, Department of Applied Physics, \\ P.O. Box 217, NL-7500 AE Enschede, The Netherlands \\ Received 20 February 1987/Accepted 3 March 1987
}

\begin{abstract}
A cryogenically cooled sealed-off x-ray preionized self-sustained discharge CO laser was succesfully operated. It was found that 20 to $40 \%$ higher output energies could be obtained using X-ray instead of uv preionization. A maximum output energy of $2.9 \mathrm{~J}$ per pulse could be extracted from a $2 \times 2 \times 40 \mathrm{~cm}^{3}$ discharge volume. The maximum electrical efficiency proved to be $12.6 \%$.
\end{abstract}

PACS: 42.55 E

It is well known that efficient high energy pulsed $\mathrm{CO}$ lasers can be built exploiting electron beam-sustained discharge techniques. The efficiency of these lasers is superior to that of similar $\mathrm{CO}_{2}$ lasers. Already in 1974 Mann et al. [1] reported output energies of $150 \mathrm{~J}$ per pulse obtained from a 21 discharge volume with an electrical efficiency of $63 \% .1600 \mathrm{~J}$ output pulses were reported by Boness and Center [2] in 1977, extracted from a 161 discharge volume with an electrical efficiency of about $40 \%$.

However, the construction of an efficient selfsustained discharge CO laser appeared to be much more difficult, especially for large apertures. The first self-sustained laser was reported in 1974 by Cohn [3] who extracted $200 \mathrm{~mJ}$ pulses from a $2.5 \times 5 \times 50 \mathrm{~cm}^{3}$ discharge with an electrical efficiency of $1.8 \%$. In 1978 Schmid [4] obtained $5 \mathbf{J}$ pulses from a $5 \times 5 \times 50 \mathrm{~cm}^{3}$ discharge with an electrical efficiency of $2 \%$. Higher efficiencies were for the first time reported by Peters [5] in 1978. He obtained $625 \mathrm{~mJ}$ pulses from a $1 \times 1 \times 60 \mathrm{~cm}^{3}$ discharge with an electrical efficiency of $15.6 \%$. In 1981 Peters [6] reported the same energy from a $1 \times 1 \times 18 \mathrm{~cm}^{3}$ discharge with an electrical efficiency of $12.1 \%$.

An important characteristic of a self-sustained discharge is the need of a certain amount of homogeneous preionization [7]. Commonly uv photons are used to achieve this preionization.

However, uv photons have severe limitations as a preionization source. Due to absorption and to their low energy they have a short range and are mainly acting upon heavy atoms and molecules such as Xe and organic impurities present in the gas mixture or upon the electrodes resulting in an inhomogeneous preionization. So in general obtaining sufficient homogeneous preionization will become more difficult using larger apertures and higher gas pressures. Moreover, in the case of $\mathrm{CO}$ heavy atoms and molecules are frozen out of the lasergas because for efficient operation the lasergas has to be cooled down to cryogenic temperatures.

In the present paper the performances of a selfsustained discharge $\mathrm{CO}$ laser, using $\mathrm{x}$-ray preionization, will be discussed. Earlier this preionization technique proved to be superior in the case of RGH[8] and high pressure $\mathrm{CO}_{2}$-lasers [9] but up to now no experiments with $\mathrm{CO}$ have been reported.

$2.8 \mathrm{~J}$ output pulses were extracted from a $2 \times 2 \times 40 \mathrm{~cm}^{3}$ discharge volume with an electrical efficiency of $10 \%$. Because the system could also be operated with a corona type uv preionization scheme it was possible to study the difference in performance between the uv and the $\mathrm{x}$-ray preionized system. It was found that $20-40 \%$ higher output energies could be obtained using $x$-ray instead of uv preionization.

\section{Construction Details}

The laser is equiped with two aluminum uniform field electrodes profiled according to a publication of 

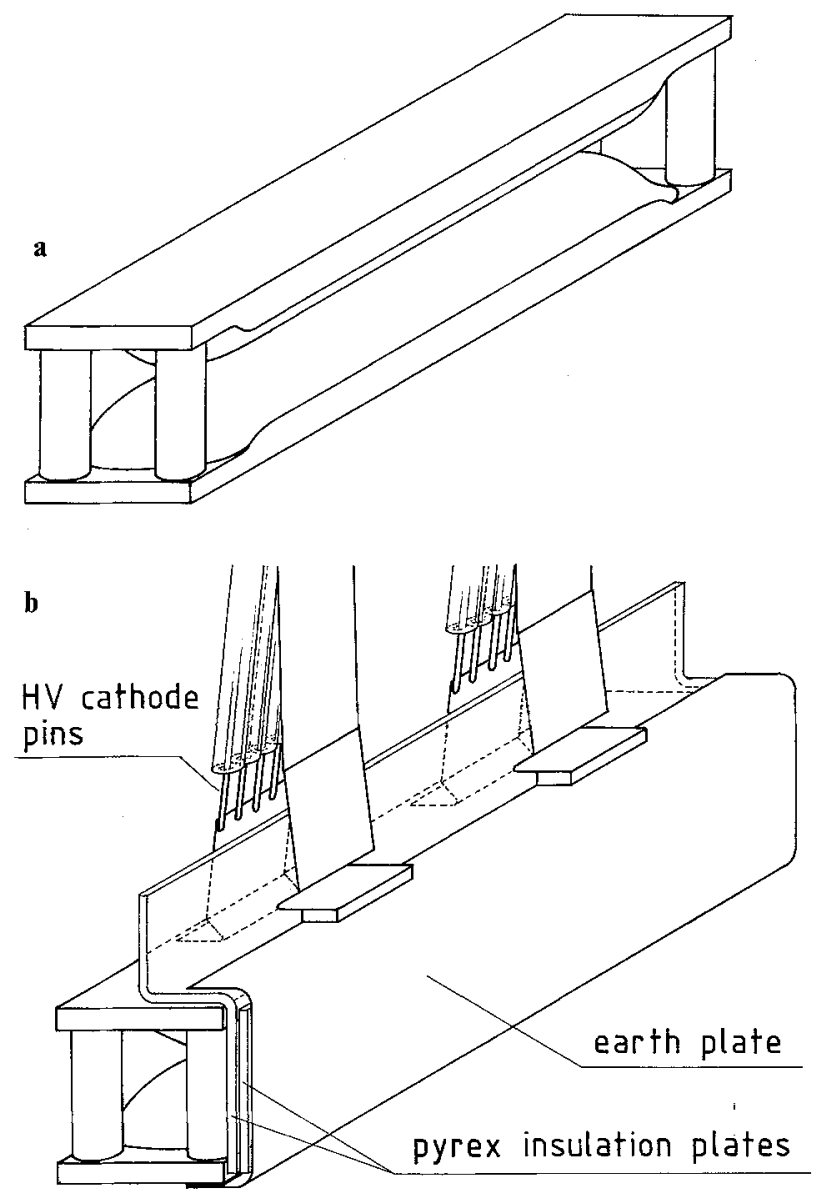

Fig. 1. (a) Laser electrodes profiled according to Chang held apart. by four quartz spacers. (b) Basic construction for experiments with uv preionization. For the $\mathrm{x}$-ray experiment a much thicker pyrex plate has been used and the earth plate has been replaced by two stips

Chang [10] with $k=0.02$ and $v=\arccos (-k)$. The electrodes are held apart by four quartz rods all precisely polished to the same length, as is shown in Fig. 1a. The discharge dimensions are $2 \times 2 \times 40 \mathrm{~cm}^{3}$.

Experiments with uv preionization were performed using a construction for uv production described by Ernst and Boer [11] and based on a corona discharge. The basic construction we used is shown in Fig. 1b. A brass plate extending the anode is mounted along one side of the electrodes while a pyrex plate is providing electrical insulation. During the initial voltage rise a corona discharge will start in the high electric field strength region near the cathode and develop along the glass plate towards the anode, meanwhile preionizing the laserglas. Also indicated are the negative highvoltage and ground connections, the former one being a multipin construction.

For the uv preionized configuration and also for the first attemps with $x$-ray preionization an optimized total thickness of $4.7 \mathrm{~mm}$ for the pyrex glass plates has
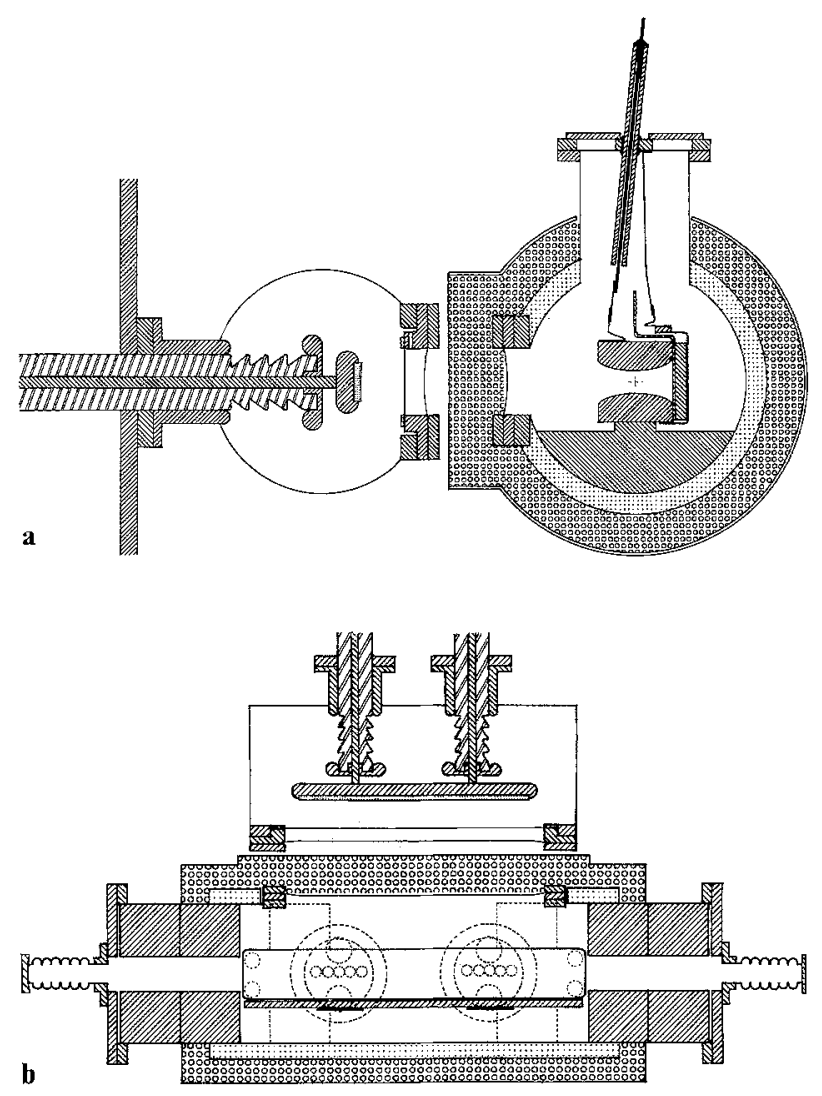

Fig. $2 a$ and b. Schematic cross-sections of the system showing the $\mathrm{x}$-ray source and the electrodes mounted inside the laser chamber

been used. For all later experiments with x-ray preionization we used the same construction however in order to suppress the corona discharge the thickness of the insulation plate has been increased to over $12 \mathrm{~mm}$ and the brass anode extension has been replaced by two $7 \mathrm{~cm}$ wide brass strips.

In Fig. 2 are shown two schematic cross-sections of the x-ray source and the laser chamber. The electrode system is mounted inside the laser chamber using two perspex supports.

The laser chamber essentially consists of a stainless steel tube with an internal diameter of $20 \mathrm{~cm}$ and a length of $87 \mathrm{~cm}$. Over a length of $60 \mathrm{~cm}$ the tube is surrounded by a second stainless steel tube with an internal diameter of $24.5 \mathrm{~cm}$, thus forming a reservoir for liquid nitrogen. Insulation is taken care of by a $3.5 \mathrm{~cm}$ thick layer of foam. Two perspex blocs are positioned at both sides of the laser chamber in order to decrease the gas volume and to prevent convection. The operating gas temperature is about $100 \mathrm{~K}$.

The optimized optical cavity was formed by a $5 \mathrm{~cm}$ diameter $80 \%$ R/AR coated flat $\mathrm{Ge}$ outcoupling mirror and a $5 \mathrm{~cm}$ diameter curved Au-coated Al total reflector with a radius of curvature of $5 \mathrm{~m}$. Cavity length was about $135 \mathrm{~cm}$. 


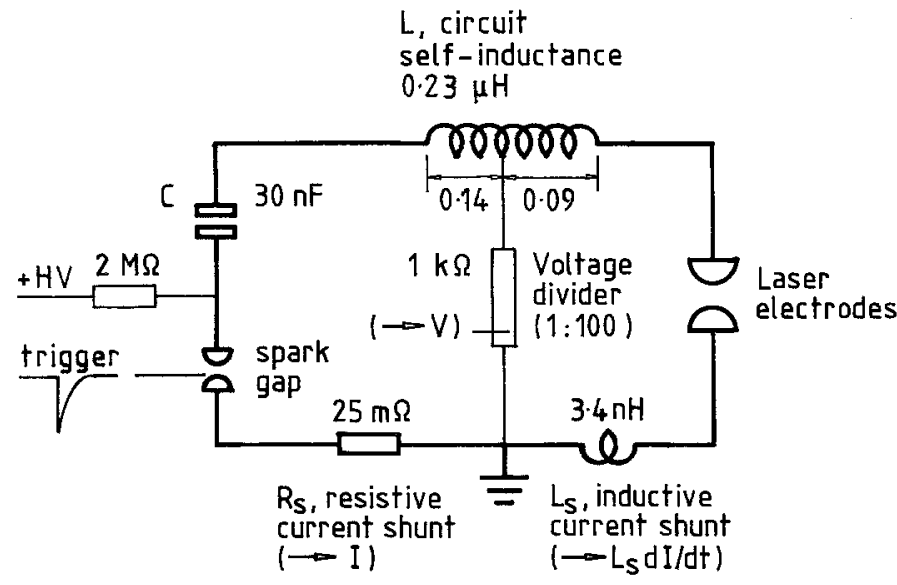

Fig. 3. Schematic representation of the laser electrical circuit

The $\mathrm{x}$-rays are produced by decelerating fast electrons in a $10 \mu \mathrm{m}$ thick Ta foil. The electrons are produced by a cold cathode $e$-beam machine driven by a two stage Marx generator equipped with two $40 \mathrm{nF}$ capacitors. The Ta foil served as the e-beam anode. During the deceleration process bremsstrahlung is produced which can leave the chamber through a $50 \mu \mathrm{m}$ thick Ti foil. The latter foil is also holding the vacuum. Diode closure time is about $2.5 \mu \mathrm{s}$, maximum foil dimensions are $6 \mathrm{~cm} \times 38 \mathrm{~cm}$, generator charging voltage is $35 \mathrm{kV}$.

The $\mathrm{x}$-ray photons enter the laser chamber through the insulating foam and through a $50 \mu \mathrm{m}$ thick Ti foil of the same dimensions as the exit foil of the x-ray source. Using a dosimeter located just behind this foil inside the laser chamber an average dose of $10 \mathrm{mR} / \mathrm{shot}$ was found under room temperature conditions.

The delay between the $\mathrm{x}$-ray pulse and the main discharge of the laser is defined as the interval of time between the onset of the voltage pulse across the e-beam diode and the onset of the laser current pulse. Unless stated otherwise a delay of about $1 \mu$ s is used.

The results presented in this paper were obtained using two different generators driving the main discharge of the laser: a two-stage Marx generator equiped with two $40 \mathrm{nF}$ capacitors and a single stage generator equiped with one $30 \mathrm{nF}$ capacitor, as presented in Fig. 3. The respective total circuit selfinductances were 0.275 and $0.23 \mu \mathrm{H}$.

Build-in diagnostics are a resistive and an inductive current shunt, both incorporated in the main circuit, and a voltage divider. Referring to Fig. 3 the voltage across the electrodes was deduced from the signal obtained from the voltage divider and the signal obtained from the inductive current shunt by $V_{\text {laser }}(t)$ $=V_{\text {divider }}(t)+0.09 \times 10^{-6} d I(t) / d t$.

\section{Characteristics of the $x$-Ray Preionized TEA CO Laser}

At first experiments have been carried out with the uv preionized system shown in Fig. 1b. The optimized gasmixture contained 0.08 Torr $\mathrm{O}_{2}, 2.9$ Torr $\mathrm{CO}$, 19.1 Torr $\mathrm{N}_{2}$, and 153 Torr He at a temperature of $100 \mathrm{~K}$. A single-stage puls generator equiped with a $30 \mathrm{nF}$ capacitor has been used. Reproducible laser output was obtained, as indicated in Fig. 4 curve 1. After switching on the $x$-ray source no reproducible laser output could be obtained with the combined $\mathrm{x}$-ray and uv preionization. This in contrast with results obtained with a $\mathrm{CO}_{2}: \mathrm{N}_{2}: \mathrm{He}=1: 1: 7$ mixture at 700 Torr and $293 \mathrm{~K}$, where an increased output energy was obtained as the result of the additional x-ray preionization. Good reproducible laser output with the $\mathrm{CO}$ mixture could only be obtained after eliminating the corona discharge by increasing the thickness of the insulating glass-plates. In fact, $20 \%$ higher output energies were obtained.

All further results presented in this section are obtained using $\mathrm{x}$-ray preionization only.

In varying the gas mixture with the $x$-ray preionized system a different optimum composition was

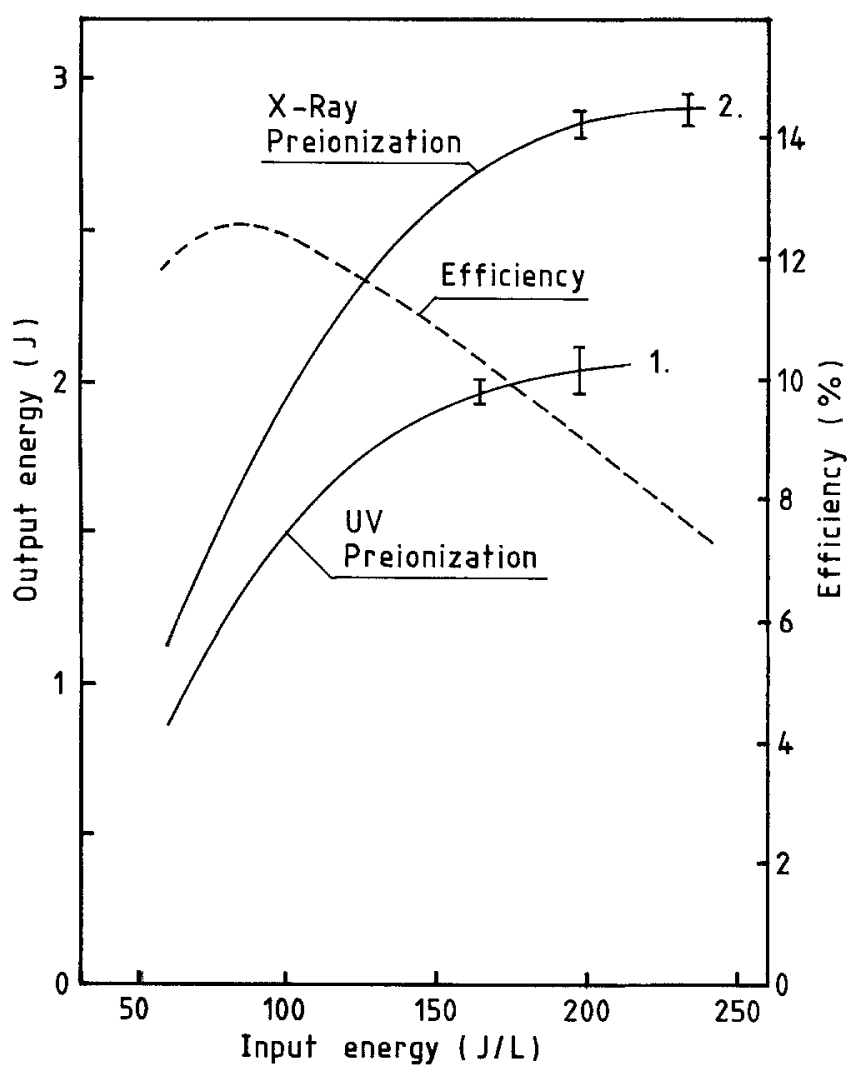

Fig. 4. Output energy of the laser plotted as a function of the input energy given in $\mathbf{J}$ per liter discharge volume both for the uv (Curve 1) and the x-ray preionized (Curve 2) system. The efficiency is plotted for the $\mathrm{x}$-ray preionized results $(C=30 \mathrm{nF})$ 
found. Especially the oxygen pressure could be increased yielding a maximum output energy of $2.9 \mathrm{~J}$ and a maximum efficiency of $12.6 \%$, as indicated in Fig. 4 curve 2. The new optimized gas mixture contained 0.29 Torr $\mathrm{O}_{2}, 4.4$ Torr $\mathrm{CO}, 29.3$ Torr $\mathrm{N}_{2}$, and 150 Torr He.

The calculated total preionization electron density deposited into the lasergas by the $\mathrm{x}$-ray pulse was $1.6 \times 10^{6}$ electrons per $\mathrm{cm}^{3}$. This amount could be decreased to a calculated value of $3.5 \times 10^{4}$ by inserting a $100 \mu \mathrm{m}$ Ta foil between the $\mathrm{x}$-ray source and the laser chamber. In this way the influence of the $x$-ray intensity on the laser output could be determined. The measured maximum output energy was found to reduce to $85 \%$ of its original value.

Increasing the total preionization electron density by increasing the charging voltage or the total capacity in the Marx generator or both, no higher output energies were obtained.

\subsection{The Effect of $\mathrm{O}_{2}$}

$\mathrm{O}_{2}$ was demonstrated to be an important additive to the laser gas mixture of an x-ray preionized selfsustained discharge $\mathrm{CO}$ laser. In Fig. 5 the output energy of the laser is plotted as a function of the input energy using different amounts of $\mathrm{O}_{2}$ and different delays between the $\mathrm{x}$-ray pulse and the main discharge of the laser. Two effects are seen as the result of the addition of small amounts of $\mathrm{O}_{2}$. Firstly, higher output

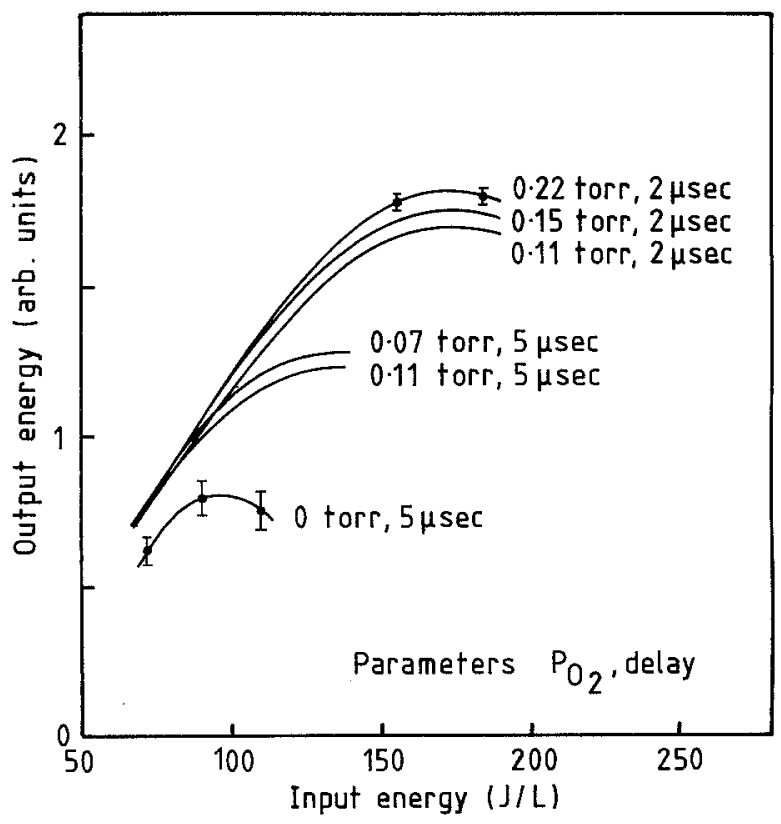

Fig. 5. Output energy as a function of the input energy using different amounts of $\mathrm{O}_{2}$ and different delays between the x-ray source and the main discharge of the laser $(C=20 \mathrm{nF})$ energies and efficiencies are obtained for the same input energy while at the same time higher input energies can be deposited into the discharge. Secondly, the maximum permittable delay between the $\mathrm{x}$-ray pulse and the main discharge decreases with increasing amounts of oxygen. For instance, for 0.11 Torr the maximum delay is about $2 \mu \mathrm{s}$. Increasing the delay to $5 \mu$ sives a much lower output energy and efficiency as is shown in the figure. The effect on output and efficiency saturates for amounts of $\mathrm{O}_{2}$ exceeding 0.20 Torr and remains constant at least up to 0.40 Torr. The laser gas mixture additionally contained 2.7 Torr CO, 18.3 Torr $\mathrm{N}_{2}$, and 150 Torr He. The pulse generator was a twostage Marx generator equiped with two $40 \mathrm{nF}$ capacitors. The optical resonator was not optimized.

The beneficial effect of $\mathrm{O}_{2}$ on the output characteristics of $\mathrm{CO}$ lasers is well known for $\mathrm{cW}$ operated systems, although the discussion about the responsible mechanism is running now for over 15 years $[12,13]$. The beneficial effect of $\mathrm{O}_{2}$ on the output energy and efficiency of a pulsed self-sustained device was first noticed by Peters [6] in 1981 using uv preionization. The mechanism responsible for this increase in efficiency and output energy is not understood up to now. It is important to note that we found that the current density and the voltage across the laser electrodes as a function of time are not effected by the addition of $\mathrm{O}_{2}$. The mechanism responsible for the decrease of the maximum permittable delay for increasing amounts of $\mathrm{O}_{2}$ most likely is the three-body attachment of thermal energy preionization electrons to $\mathrm{O}_{2}$ molecules. This mechanism was earlier proposed by Norris and Smith [14] in 1977 for an uv preionized TEA $\mathrm{CO}_{2}$ laser in which $\mathrm{O}_{2}$ appeared as a dissociation product. The actual process was first described by Chanin et al. [15] in 1962.

In Fig. 6 the output energy of the laser is plotted as a function of the delay between the X-ray pulse and the main discharge of the laser. The input energy was $165 \mathrm{~J} / \mathrm{L}$.

The initial electron density created by the $\mathrm{x}$-ray pulse will decrease during the delay because of the attachment processes. This causes the rapid decay of the output energy of the laser as a function of the delay. A less rapid decay is found for lower input energies, demanding lower preionization densities, and smaller amounts of $\mathrm{O}_{2}$, leading to a smaller number of attachment processes. A constant output energy is found for delays exceeding $20 \mu \mathrm{s}$, due to the fact that the system is still capable of some corona formation. The same output energy is found with the $x$-ray source switched-off. Highly non-reproducible output energies are obtained for those delays where the effect of the $\mathrm{x}$-ray pulse seems to equal the effect of the corona discharge. For those circumstances arcing of the 


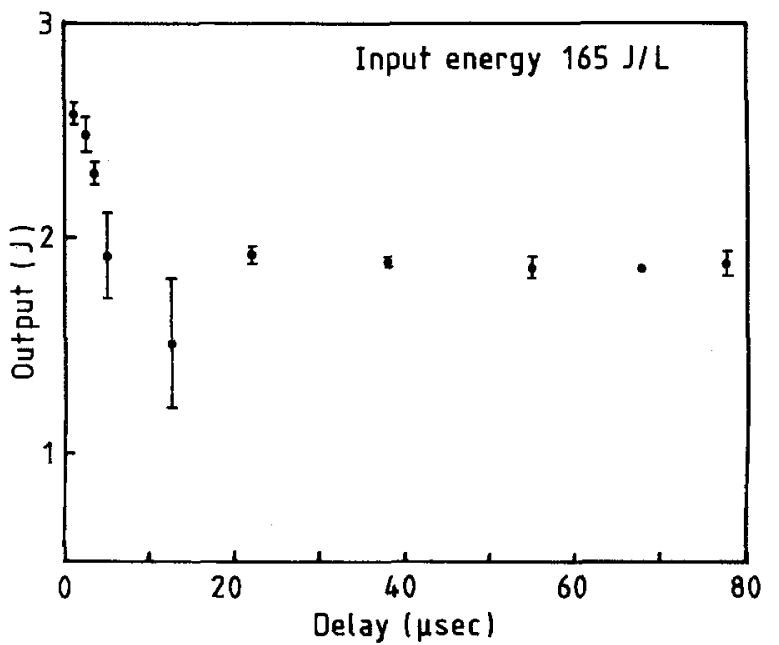

Fig. 6. Output energy of the laser plotted as a function of the delay between the $\mathrm{x}$-ray pulse and the main discharge of the laser $(C=20 \mathrm{nF})$

discharge could be observed which is probably due to inhomogeneous preionization.

\subsection{The Effect of $\mathrm{He}$}

The effect of the addition of $\mathrm{He}$ to given amounts of $\mathrm{O}_{2}$, $\mathrm{CO}$, and $\mathrm{N}_{2}$ was studied. The amounts of $\mathrm{O}_{2}, \mathrm{CO}$, and $\mathrm{N}_{2}$ relative to each other were kept according to $P_{\mathrm{O}_{2}}: P_{\mathrm{CO}}: P_{\mathrm{N}_{2}}=1: 15: 100$. The total amount of $\mathrm{O}_{2}$, $\mathrm{CO}$, and $\mathrm{N}_{2}$ will be referred to as the total amount of heavy particles.

In Fig. 7 the output energy of the laser is plotted as a function of the amount of $\mathrm{He}$ added to given amounts of heavy particles. The input energy is used as a parameter.

The following characteristics are found. For a given amount of heavy particles and a given input energy there turns out to be an optimum amount of added He. Furtheron, for a given amount of heavy particles higher values for the optimum amount of added $\mathrm{He}$ are found for higher input energies. And also for a given amount of heavy particles the output energy obtained by adding the optimum amount of $\mathrm{He}$ saturates for high input energies. Finally, the maximum output energy is found to increase with increasing amounts of heavy particles, up to about 34 Torr. Exceeding this amount the effect saturates and finally the discharge becomes unstable.

In Fig. 8 the same data are plotted as a function of the input energy with the amount of added He used as a parameter.

There are at least two processes in which the $\mathrm{He}$ is involved. On one hand, He serves as a thermal bath taking up the excess energy during vibration-vibration energy exchange processes, on the other hand, $\mathrm{He}$ is
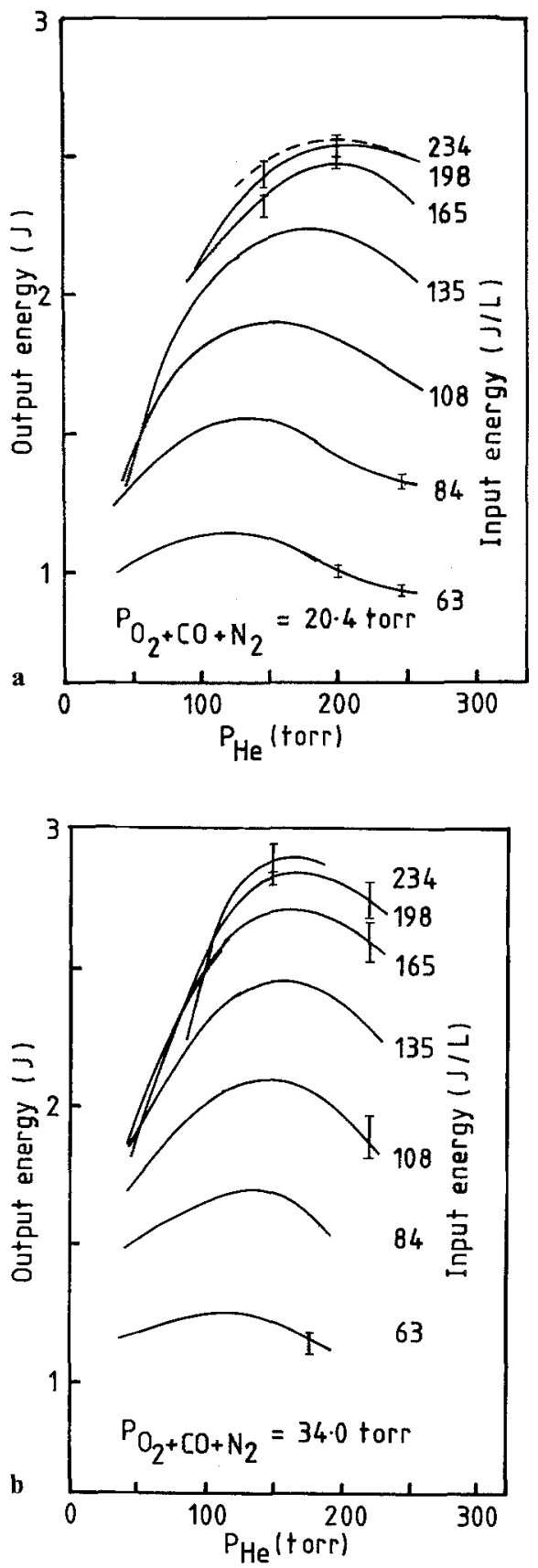

Fig. $7 \mathrm{a}$ and $\mathrm{b}$. Output energy of the laser plotted as a function of the amount of He added to given amounts of heavy particles. The input energy is used as a parameter $P_{\mathrm{O}_{2}}: P_{\mathrm{CO}}: P_{\mathrm{N}_{2}}=1: 15: 100$ $(C=30 \mathrm{nF})$

responsible for an increased loss of vibrational energy because of vibration-translation relaxation processes. These processes are responsible for the appearance of an optimum amount of added $\mathrm{He}$.

The saturating effect at high input energies is assumed to be due to increasing discharge instabilities during every pulse. In fact, a greater amount of current will be carried by arcs. The saturating effect at high 


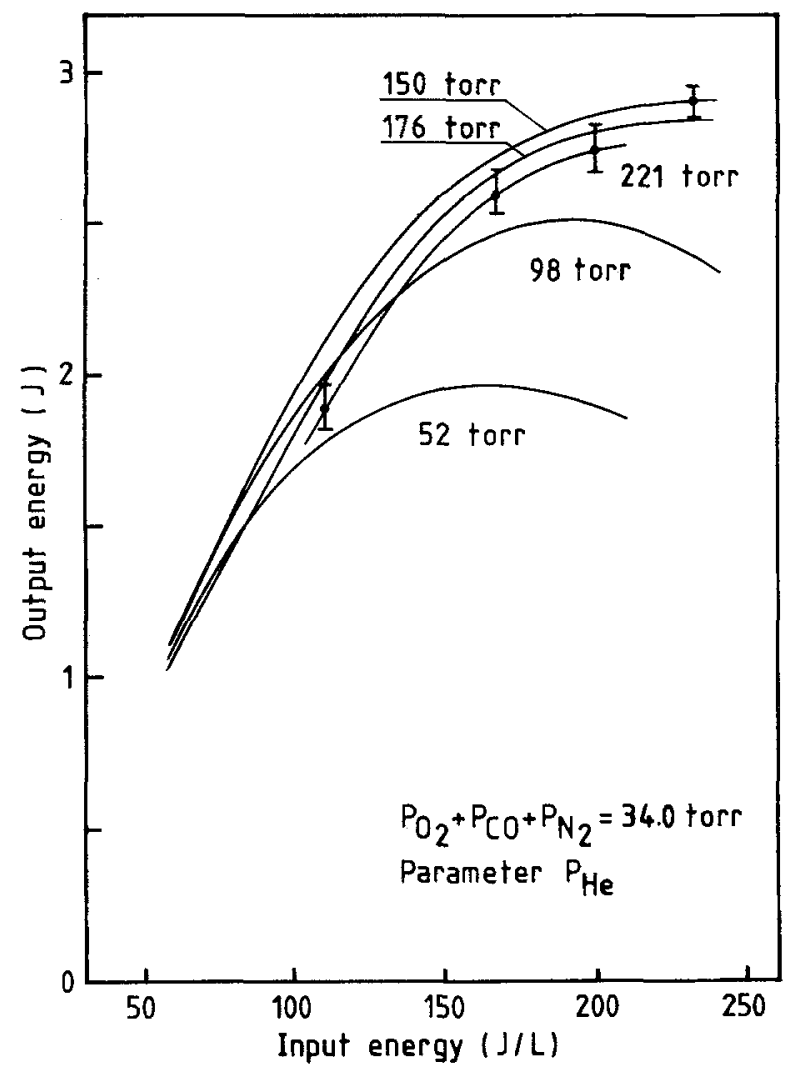

Fig. 8. Same data as in Fig. 7 plotted as a function of the input energy with the amount of $\mathrm{He}$ used as a parameter

amounts of heavy particles is also due to a growing probability of severe arcing measured over many pulses because of the increased electrical pulse length. Voltage and current characteristics supporting these assumptions are presented in Sect. 2.4.

\subsection{The Effect of $\mathrm{N}_{2}$}

In Fig. 9 the output energy of the laser is plotted as a function of the input energy using different amounts of $\mathrm{N}_{2}$. Starting with a mixture composed according to $P_{\mathrm{O}_{2}}=0.28$ Torr, $P_{\mathrm{CO}}=4.3$ Torr, $P_{\mathrm{N}_{2}}=9.1$ Torr, and $P_{\mathrm{He}}=146$ Torr the amount of $\mathrm{N}_{2}$ was increased to 17.1 and 27.1 Torr. Upon further increasing of the amount of $\mathrm{N}_{2}$ up to 34 Torr slightly lower output energies were obtained.

The output power was found to remain essentially unchanged as a function of time for the different amounts of $\mathrm{N}_{2}$. This confirms that the most important effect of $\mathrm{N}_{2}$ is to alter the electron distribution function in such a way that the $\mathrm{CO}$ vibrational excitation rate by electron impact is enhanced [16]. Its functioning as a storage reservoir for vibrational energy is of less importance. A typical plot of the output power as a function of time is given in Fig. 10.

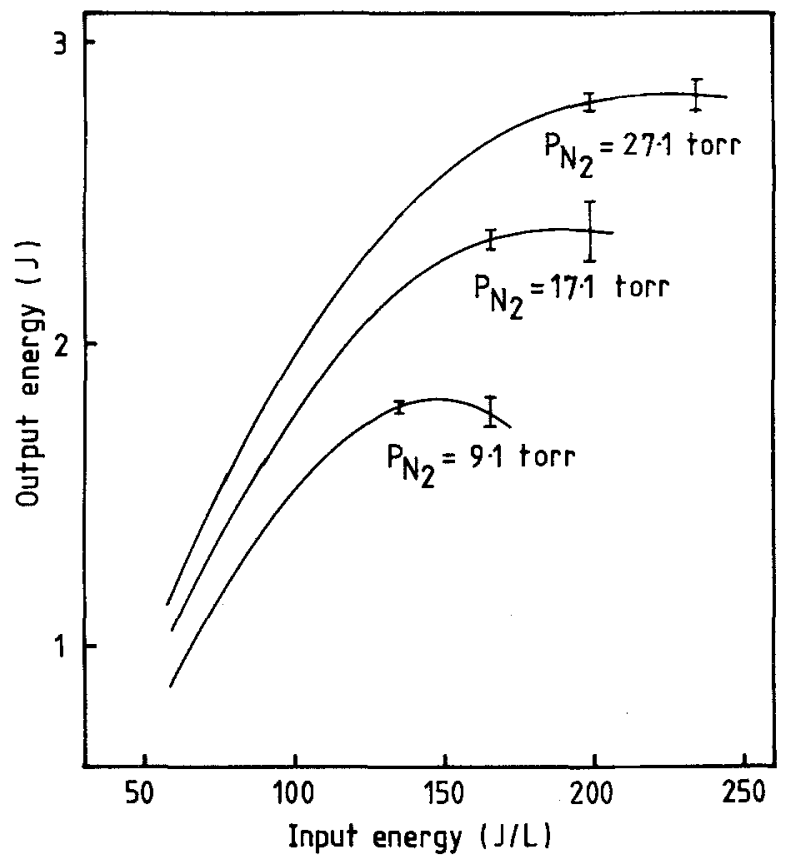

Fig. 9. Output energy of the laser plotted as a function of the input energy using different amounts of $\mathrm{N}_{2}(C=30 \mathrm{nF})$

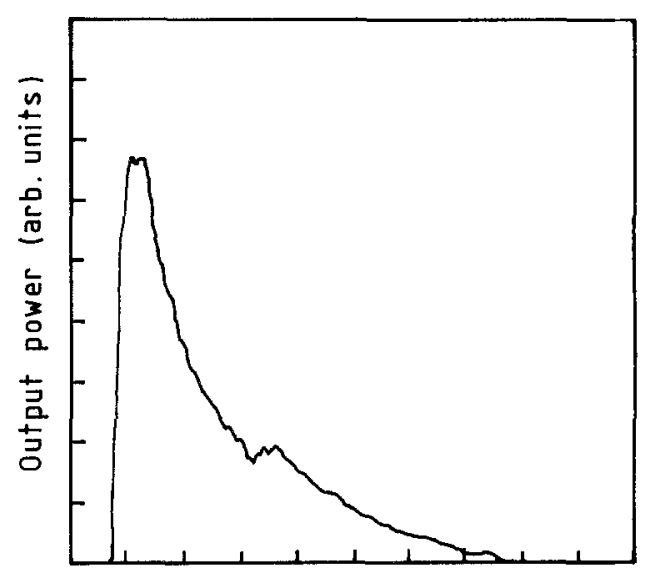

Time $(50 \mu \mathrm{sec} / \mathrm{div})$

Fig. 10. Optical output power plotted as a function of time. The input energy is $135 \mathrm{~J} / \mathrm{l}(C=30 \mathrm{nF})$

\subsection{Electrical Characteristics}

The electrical characteristics of the discharge of the laser are governed by the gas mixture composition and the input energy. With respect to the gas mixture composition especially the fractional amount of heavy particles and the total pressure are important.

In Fig. $11 \mathrm{a}-\mathrm{c}$ the voltage and current characteristics are plotted for constant gas mixture composition and increasing input energies. Figure $12 \mathrm{a}-\mathrm{c}$ are showing the effect of increasing fractional amounts of heavy particles and total pressures for constant input energy. The probability of severe arcing, measured over many 

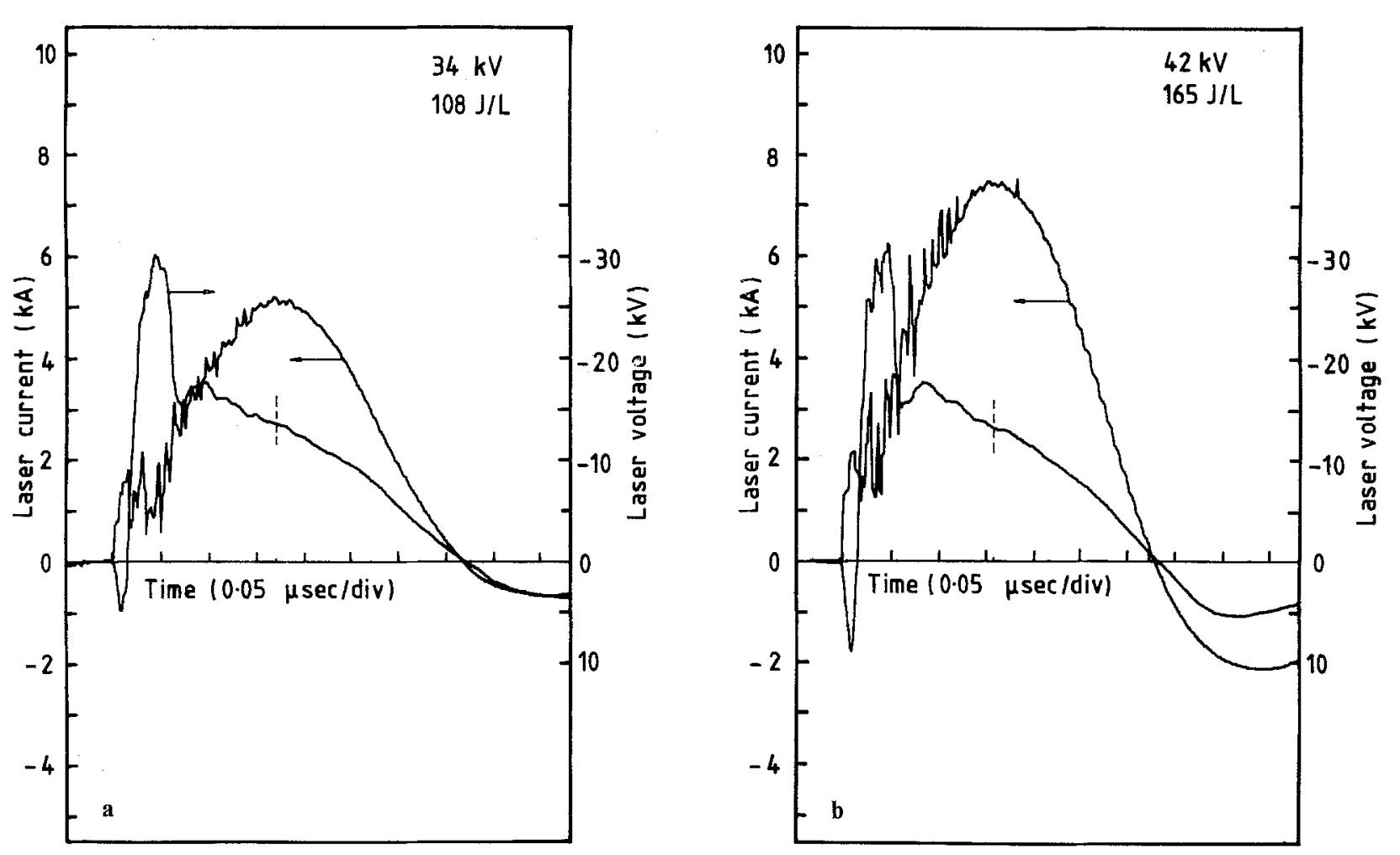

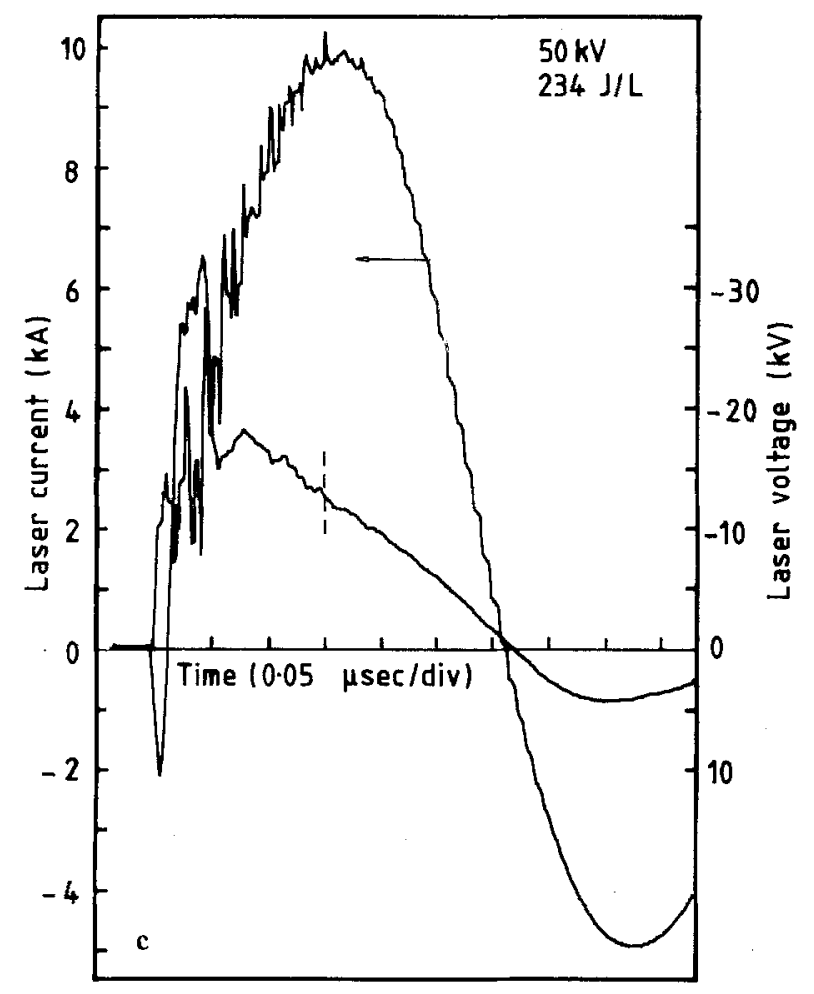

pulses was found to increase for increasing fractional amounts of heavy particles and total pressures, probably because of the increasing electrical pulse length. No arcing occurred for the characteristics presented in Fig. 12.
Fig. 11a-c. Voltage and current characteristics of the laser discharge for constant gas mixture composition and different input energies $(C=30 \mathrm{nF}), P_{\mathrm{O}_{2}}=0.29$ Torr, $P_{\mathrm{CO}}=4.4$ Torr, $P_{\mathrm{N}_{2}}=29.3$ Torr, $P_{\mathrm{He}}=150$ Torr)

The quasi-steady state voltage $V^{*}$, taken as the voltage at $(d I / d t)=0$, was found to be a function of the gas mixture composition only according to $V^{*}=A P_{\text {tot }}+B$ with the constants $A$ and $B$ depending upon the fractional amount of heavy particles, thus 

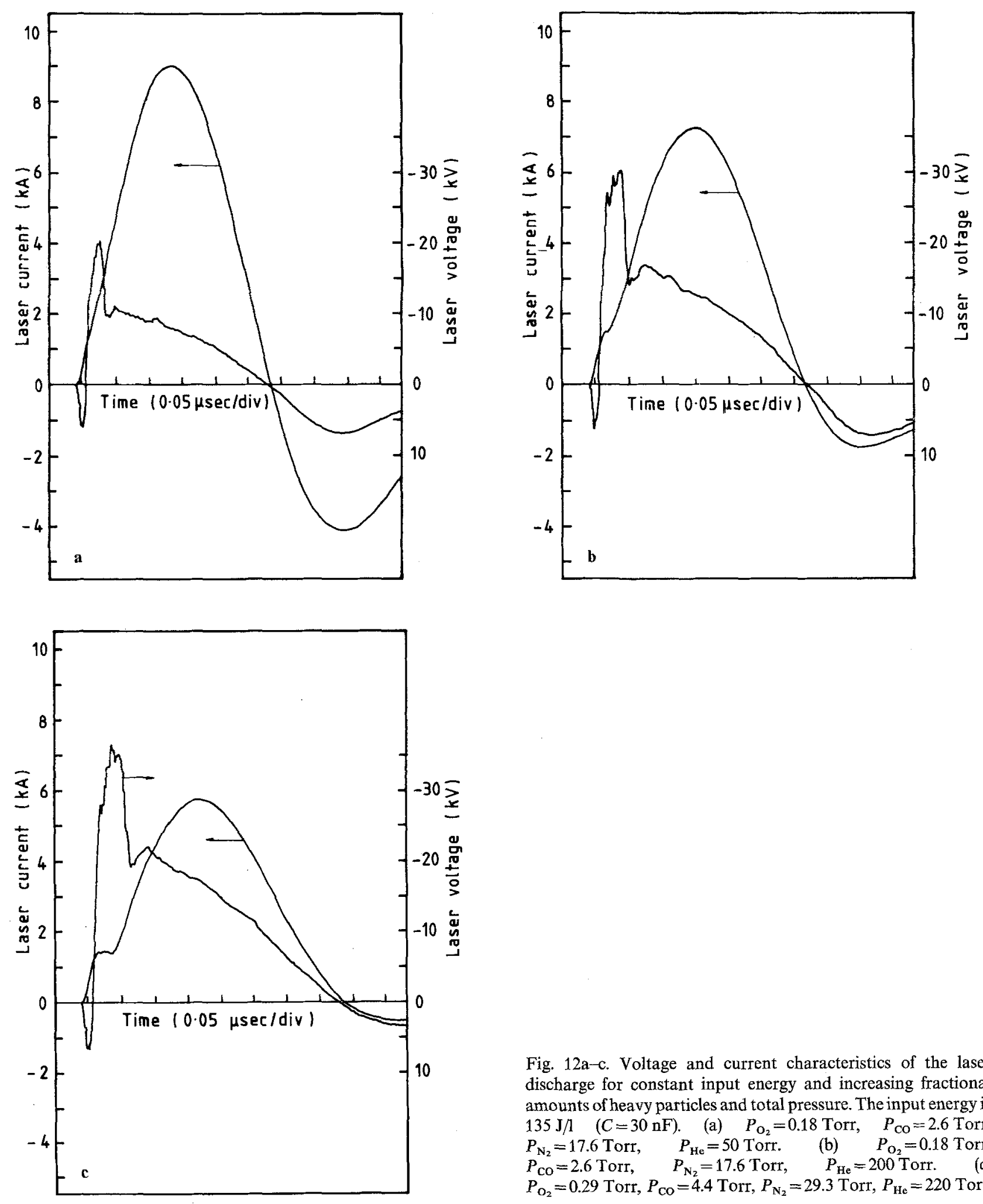

Fig. 12a-c. Voltage and current characteristics of the laser discharge for constant input energy and increasing fractional amounts of heavy particles and total pressure. The input energy is $135 \mathrm{~J} / 1 \quad(C=30 \mathrm{nF})$. (a) $P_{\mathrm{O}_{2}}=0.18 \mathrm{Torr}, \quad P_{\mathrm{CO}}=2.6$ Torr, $P_{\mathrm{N}_{2}}=17.6$ Torr, $\quad P_{\mathrm{He}}=50$ Torr. (b) $\quad P_{\mathrm{O}_{2}}=0.18$ Torr, $P_{\mathrm{CO}}=2.6$ Torr, $\quad P_{\mathrm{N}_{2}}=17.6$ Torr, $\quad P_{\mathrm{He}}=200$ Torr. (c) $P_{\mathrm{O}_{2}}=0.29$ Torr, $P_{\mathrm{CO}}=4.4$ Torr, $P_{\mathrm{N}_{2}}=29.3$ Torr, $P_{\mathrm{He}}=220$ Torr 
demonstrating an attachment dominated discharge. The constant $B$, representing the cathode fall in potential was found to be in the order of $3 \mathrm{kV}$.

\section{Comparison Between $x-R a y$ and uv Preionization}

As was pointed out in Sect. 2 an electrode configuration with reduced uv preionization capabilities has been used for the experiments with $x$-ray preionization. In Fig. 4 curve 2 the output energy of the laser is plotted as a function of the input energy for our $x$-ray preionized system under optimized conditions which means a gas mixture composed of $P_{\mathrm{O}_{2}}=0.29$ Torr, $P_{\mathrm{CO}}=4.4$ Torr, $P_{\mathrm{N}_{2}}=29.3$ Torr, and $P_{\mathrm{He}}=150$ Torr and a single stage pulse generator having one $30 \mathrm{nF}$ capacitor.

It was not possible to obtain reproducible output energies from an electrode configuration with optimized uv preionization for this mixture because the oxygen partial pressure was too high to obtain a reliable discharge. For such a configuration good results could only be obtained if the oxygen partial pressure was reduced to $P_{\mathrm{O}_{2}}=0.08$ Torr. Curve 1 of Fig. 4 shows a plot of those output energy measurements. Also the other partial pressures were somewhat lower viz. $P_{\mathrm{CO}}=2.9$ Torr, $P_{\mathrm{N}_{2}}=19.1$ Torr, and $P_{\mathrm{He}}=153$ Torr.

From these measurements it can be learned that $x$-ray preionization has a considerable advantage because it makes it possible to obtain a reliable discharge for mixtures containing a high oxygen partial pressure and such mixtures are able to produce higher output energies and better efficiencies.

\section{Summary}

Oxygen is found to be a very important additive to the laser gas mixture of a self-sustained discharge TEA CO laser. It has a strong beneficial effect on the output characteristics because the output energy as well as the efficiency increases considerably. The effect saturates for high amounts of oxygen. Moreover, oxygen has a detrimental effect on the preionization density, which means that the system has to be fast enough to take full advantage of the improved performance capabilities of an oxygen-rich mixture.

Using the corona based uv preionization scheme presented in this paper it is not possible to take full profit of the beneficial effect of $\mathrm{O}_{2}$. The total amount of oxygen that can be added to the laser gas mixture is limited to $P_{\mathrm{O}_{2}}=0.08$ Torr, yielding a maximum output energy of $2.1 \mathrm{~J}$. On the other hand, using the $\mathrm{x}$-ray preionization scheme there seems to be not such a limitation. Using 0.29 Torr of oxygen a maximum output energy of $2.9 \mathrm{~J}$ could be obtained which means an increase of $38 \%$ compared with uv preionization. The maximum efficiency we could obtain is $12.6 \%$.

\section{References}

1. M.M. Mann, D.K. Rice, R.G. Eguchi: IEEE J. QE-10, 682-683 (1974)

2. M.J.W. Boness, R.E. Center: J. Appl. Phys. 48, 2705-2711 (1977)

3. D.B. Cohn: IEEE J. QE-10, 459-461 (1974)

4. W.E. Schmid: A simple high-energy TEA CO laser, in High Power Laser and Applications, ed. by K.-L. Kompa, $\mathbf{H}$. Walther, Springer Ser. Opt. Sci. 9 (Springer, Berlin, Heidelberg 1978) pp. 148-153

5. P.J.M. Peters: Opt. Commun. 25, 241--243 (1978)

6. P.J.M. Peters: Efficient high output energy CO laser; construction details and delay time studies, Dissertation, Twente University of Technology, The Netherlands (1981)

7. J.I. Levatter, Shao-Chi Lin: J. Appl. Phys. 51, 210-222 (1980)

8. K. Midorikawa, M. Obara, T. Fujioka: IEEE J. QE-20, 195-205 (1984)

9. K. Jayaram, A.J. Alcock: J. Appl. Phys. 58, 1719-1726 (1985)

10. T.Y. Chang: Rev. Sci. Instrum. 44, 405-407 (1973)

11. G.J. Ernst, A.G. Boer: Opt. Commun. 27, 105-110 (1978)

12. G.A. Murray, A.L.S. Smith: J. Phys. D 14, 1745-1756 (1981)

13. Yu.M. Kagan, Y. Kaufman: J. Phys. D 16, 1687-1699 (1983)

14. B. Norris, A.L.S. Smith: J. Phys. D 10, L237-240 (1977)

15. L.M. Chamin, A.V. Phelps, M.A. Biondi: Phys. Rev. 128, 219-230 (1962)

16. R.E. Center: High-Power, efficient electrically excited CO lasers, in Laser Handbook, Vol. 3, ed. by M.L. Stitch (NorthHolland, Amsterdam 1979) pp. 103-104 